\title{
Editorial
}

\section{Enhancing the effectiveness of the 21st century board of directors}

\author{
International Journal of Disclosure and Governance (2013) 10, 93-97. doi:10.1057/jdg.2013.20
}

Welcome to the first of two issues of this Special Edition of the International Journal of Disclosure and Governance entitled 'Enhancing the Effectiveness of the 21st Century Board of Directors'. We have six papers herein, including a mixture of academic and practitioner articles, qualitative and quantitative research, gender and geography and subject matter areas.

The focus of this first issue will be on three areas that are critically important to the field of corporate governance at present: the governance of risk management; the governance of executive compensation; and the skills, competencies and behaviours of board chairs and directors.

We have six excellent papers to follow in this issue: (i) '[A] Message from the Chair on Introducing Enterprise Risk Management (ERM) to a Company', by John R.S. Fraser; (ii) 'Perspectives on the Decision-Making Style of the Board Chair', by Dr Abigail Levrau and Professor dr Lutgart Van den Berghe; (iii) 'Right Reward for Right Performance: Aligning Executive Compensation with Good Governance', by Dr Y1lmaz Argüden; (iv) 'Uniform Regulation of Executive Pay at Banks - Will it Make a Difference? The Case Study of Poland', by Agnieszka SłomkaGołębiowska, PhD; (v) 'Financial Reporting Failures, Board's Competency and Effectiveness', by Aiman Nariman Mohd-Sulaiman, SJD; and (vi) 'Threats to Board Stability: Understanding SME Director Behaviour', by Solange Charas, Doctor of Management Candidate, and Dr Sheri Perelli.

Each article is described below, editing the drafting that the authors have provided and including a brief description of each author's background. We conclude with remarks by me at the end, a thanking of reviewers and a prelude of expected article subjects for the next issue. The length of the introductions below is unrelated to the articles themselves, and the articles do appear in an order. The first article refers to the governance of risk and the role of the board chair, written by a practitioner. The second article to follow hones in on the decision style of the chair, written by two academics. Articles 3 and 4 both speak to the governance of executive compensation, from a practitioner and an academic viewpoint. The remaining Articles 5 and 6 address the competencies, skills and behaviours of individual directors, both of which are written by academics. Note too that the practitioners selected have academic and writing leanings, and the academics have practitioner and advisory leanings. This mutual overlap also bodes well for the articles.

We now begin with the first two articles addressing risk and the role and behaviours of the board chair.

\section{MESSAGE FROM THE CHAIR ON INTRODUCING ERM TO A COMPANY}

ERM, as a theory and practice, has captured the attention of governance experts, boards of directors, regulators, rating agencies and senior management over the past 10 years. Although there is great interest in implementing ERM, the confusion and uncertainty about how it should be done in practical terms has led to 
a high failure rate and some degree of frustration among those who have been attempting to do so.

This article draws on John Fraser's 12 years of practical experience as a Chief Risk Officer and his academic research on ERM, and distils it into an easy-to-understand description of the process in the form of an imaginary speech by the Chair of a Board to fellow directors. The speech is highly recommended, academically grounded, based on practical experience and can be used as a template for any board chair who is serious about the governance and oversight of risk management.

This speech covers all the essentials of ERM in a clear and practical step-by-step manner. It conveys the critical importance of having meaningful conversations about risk in its many aspects, as well as having methods to prioritize the most important issues and allocate resources based on a risk methodology. These techniques, while essential in larger complex organizations, are equally effective in smaller organizations of all types.

The key techniques are: the need for and role of a risk policy, establishing risk criteria as a basis for making decisions, the use of risk workshops to generate meaningful communication about risks, the use of risk profiles for board oversight and the optimization of resources to best meet challenges to achieving strategic objectives.

John Fraser has researched, written and edited numerous academic papers on ERM, and has taught the practical methods described here to directors, senior management and academics.

\section{PERSPECTIVES ON THE DECISION-MAKING STYLE OF THE BOARD CHAIR}

Second, this study by Dr Abigail Levrau and Professor Dr Lutgart Van den Berghe investigates the decision-making style of the board chair. Findings include the following:

Board chairs vary substantially in the way they carry out their role in reaching what is supposed to be collegial decision making. This diversity is observed in the decision-making styles. Individual personalities and skills influence the style used. The model of the eye-to-eye decision making is considered to be the most effective one for collegial bodies, as is the case with boards. This occurs when the chair has a concern for decision adequacy, while at the same time sharing power with the board members and allowing all of them to be involved and make a contribution.

The board chair is also assumed to be a team and relational leader in fostering effective interactions between various parties and, as such, assuring a smooth operation of board process. A well-functioning chairman-CEO relationship is considered to be critical in cases where the roles are separated. The authors find that the process of shaping boardroom dialogue, while being confronted group dynamics, requires specific skills and techniques of a board chair.

In sum, saying that being a board chair is a challenging job is an understatement. It requires steerage for a board chair to bring out the best of his directors and make a board effective. An effective board chair requires competent directors, who understand the business, and a well-balanced skill matrix on the board of directors.

The main implication of this study for practitioners is that the discussion should no longer be on splitting or separation roles of chair and CEO, but must shift towards the decisionmaking style that the chair exposes and the way he or she interacts with other parties, including shareholders.

Abigail Levrau successfully completed her doctoral dissertation on the topic of board effectiveness. She is a member of the Management Committee of GUBERNA (The Belgian Governance Institute). She is a project leader for research projects on governance, evaluates boards and teaches in board training programs. Lutgart Van den Berghe is Doctor in Economics (Ghent University). She is the Executive Director of GUBERNA, Partner 
of Vlerick Business School and part-time Professor at Ghent University. She serves as a Non-Executive Director in various companies. Lutgart has been affiliated with universities in the Netherlands, Belgium, France, Italy, Austria and the United States.

Next, we explore the governance of executive compensation. We have two articles, written by a practitioner and an academic, in no particular order.

\section{RIGHT REWARD FOR RIGHT PERFORMANCE: ALIGNING EXECUTIVE COMPENSATION WITH GOOD GOVERNANCE}

With sound reasoning, Yilmaz Argüden indicates that, in the governance of executive compensation, one size does not fit all, and each company should establish its own compensation philosophy and structure based on its own situation. He particularly argues that understanding the key challenges, strategy and culture of the organization is a critical first step in establishing an executive compensation system in order to identify and attract the right top executives, as well as in motivating and retaining them. Dr Argüden claims that, in identifying and communicating key performance areas, the boards need to focus on balance of strategicoperational, short-term-long-term, risk-reward and financial-sustainability dimensions to signal properly their priorities.

He suggests that, to ensure competitiveness of the executive compensation system, as well as to be able to have a sound disclosure policy, proper benchmarking with peers both on relative and absolute terms is a key requirement. Regardless of the detailed upfront work to identify the key performance indicators, establishing targets, thresholds and caps, he argues that performance needs to be evaluated by the board based on their business acumen and judgement based on the original objectives. He advocates that exercising discretion is a key board responsibility that should not be delegated to a formula or unduly influenced by the selection of peer groups.
This is a convincing article that indicates that establishing and managing an executive compensation system is an art that requires continuous attention and exercising business judgement by the boards.

Dr Argüden has authored books such as Boardroom Secrets and Keys to Governance and has served on boards of more than 50 institutions. He provides a practitioner's perspective on how to establish an executive compensation system. He not only outlines a structured approach to establish and manage an executive compensation system, but also provides important hints for shaping the executive compensation for different industries and companies, based on the characteristics of the industries and the strategic position of the companies.

\section{UNIFORM REGULATION OF EXECUTIVE PAY AT BANKS - WILL IT MAKE A DIFFERENCE? THE CASE STUDY OF POLAND}

New compensation policies since the financial crisis aim to better align the interests of shareholders and depositors by determining the form, as well as payout of the variable component of executive remuneration at banks in order to limit the excessive risk taking. Local banks in most countries are closely held, and hence the protection of minority shareholders and depositors from potential expropriation by the controlling shareholder constitutes the core corporate governance problem, according to Agnieszka Słomka-Gołębiowska.

In her article, she examines how the new uniform legal rules imposed by the European Union may impact banks' executive remuneration in Poland and whether it could solve the foregoing corporate governance problem. After a comprehensive analysis, her findings show that closely held banks operating in Poland in 2010 pursued a very conservative executive remuneration policy, as cash compensation constituted more than 90 per cent of total pay, whereas fixed salary represented the most important component. Moreover, as previous research confirms, more fixed 
remuneration lowers the propensity of managers to take risk. Therefore, uniform regulation aiming to limiting the excessive risk taking in banks seems to be redundant in Poland, according to the author.

In addition, the level of total executive compensation relative to the average wage was even higher than in Western Europe, which, together with a high fraction of other benefits and severance pay in total pay, may be evidence of minority shareholder rights' violation. The link between pay and performance is rather weak because of insignificant proportion of variable compensation in total pay and limited use of share-based compensation. The latter makes implementation of the European Directive costly in Poland, similar to many countries where share-based compensation is common.

Given that there is no legal obligation for balancing executive remuneration between fixed and variable components, banks in Poland may pursue a more conservative compensation policy by increasing basic salary. This will further limit sensitivity between pay and corporate performance, as well as increase fixed costs for banks. These ultimately show that uniform regulation, regardless of a country's institutional framework, may have an adverse impact and exacerbate rather than solve the country's core problem of corporate governance.

Agnieszka Słomka-Gołębiowska is Associate Professor of Corporate Governance at the Warsaw School of Economics. She holds a $\mathrm{PhD}$ in economics defending the thesis on the bank's role in corporate governance. She has been on supervisory boards of listed companies. She is the author of Corporate Governance: Banks as Guardians of Enterprises' Effectiveness (2006), speaks at international conferences and has authored numerous publications. She co-operates with the Polish Institute of Directors.

Finally, we have two articles on the competency, skills and behaviours of individual directors, written by academics (and advisors) and in no particular order.

\section{FINANCIAL REPORTING FAILURES, BOARD'S COMPETENCY AND EFFECTIVENESS}

This article discusses the significance of directors' skill and expertise as an important governance tool. Although there has been increased recognition of the need for directors to have skill and expertise (and even special skill set), there are difficulties in interpreting, monitoring and enforcing compliance with this requirement. The article also highlights concerns as to the skill and expertise requirement's usefulness and limits. The discussion by the author, Aiman Nariman Mohd Sulaiman, has important implications for members of the board, as there are guidelines from cases decided by the court involving processes that can be internalized to minimize the liability risk of directors. These cases discussed in the article by this legal academic include Daniels $v$ Anderson (1995) 13 ACLC 614, R v. Moses [2011] NZHC 646; Davidson $v$ Registrar of Companies (2010); and Australian and Securities Investment Commission v. Healey [2011] FCA 717 (the Centro case). According to the author, the Centro case has helped to clarify the relevance of competence in the form of the financial literacy criteria where the court expects directors to have sufficient financial literacy to understand financial statements so as to guide and monitor the company's business. The case has also provided a clearer link between the self-regulatory financial literacy requirement and how the court should consider these criteria in evaluating directors' standard of care and skill.

There are important policy implications relating to how the requirements for skill and expertise can be enforced by regulators. The qualitative nature of the research (see the above discussion of cases within the article for a flavour) enables readers to visualize the law in practice and better understand the application of legal principles. Boards and regulators, according to this author, need to rethink and reconsider the suitability of current board practices and regulatory response to governance breakdowns. 
Dr Aiman Nariman Mohd Sulaiman is a Professor of Law at the Law Faculty, International Islamic University, Malaysia. Her wider research interests are on corporate law and corporate governance with particular focus on regulatory techniques and enforcement. While she is maintaining an ongoing interest in traditional corporate law issues, particularly directors' duties and shareholder empowerment, her current research focus is on enforcement strategies, the interaction between self-regulation and legal rules, as well as the Islamic perspective on those issues.

\section{THREATS TO BOARD STABILITY: UNDERSTANDING SME DIRECTOR BEHAVIOUR}

Finally, the article 'Threats to Board Stability: Understanding SME (small- and medium-sized enterprise) Director Behavior' draws on 'theatric' theory to examine boards as 'actors', whose individual and collective performances can enhance or diminish the quality of organizational governance. Semi-structured interviews with seldom-sampled US SME board members of companies rated high and low in governance quality reveal factors affecting their behaviour in and out of the post-Sarbanes-Oxley Act boardroom - and the consequences of that behaviour on board culture, tenure and overall performance.

This research should be of interest to individuals who serve on boards - both of for-profit and not-for-profit organizations, but also to executives and the myriad stakeholders affected by them. The authors' research results illustrate how board members' behaviour, both individual and collective, impacts board quality. The data also reveal relationships between governance quality and how directors are recruited to - and, when necessary, dismissed from - the board.

Conducted by practitioner-scholars with both academic and corporate credentials, the research uses strong theoretical and methodological approaches to examine a very basic, but increasingly critical, issue relevant to all organizations governed by boards. From it emerge practical ideas not only for optimizing director selection and recruitment but, consequently, board culture, operation and results.

Solange Charas, a Doctor of Management candidate at Case Western Reserve University, has 25 years of experience as a human capital consultant specializing in board advisory issues, executive remuneration and human capital optimization. Dr Sheri Perelli teaches doctoral, MBA and undergraduate programs at Wayne State University's School of Business Administration and School of Engineering and has over 30 years of international corporate management and consulting experience.

\section{CONCLUSION}

All eight authors of the above six articles are sincerely thanked for their diligence and responsiveness in responding to the many edits I proposed, as well as those of other academics, thanked below, and bringing these articles to bear. They do represent a blend of academic and practice, emerging qualitative research and key issues now of concern to boards of directors, namely, risk, compensation and the quality of board and director leadership and behaviour.

The following individuals are sincerely thanked for their reviews of some of the more quantitative articles, in this and the second issue to follow: Professor Yacine Belghitar, Cranfield University; Professor Ruth Bender, Cranfield University; Professor Gilles Bernier, Université Laval; Professor Patrice Gélinas, York University; and Professor Jacques Grisé, Université Laval.

The second issue to follow is expected to focus on board leadership, challenge, capital and strategy; the governance of enterprise technology and technological literacy; and governance disclosure and firm value.

We hope you enjoy the quality of the articles herein.

Richard Leblanc Special Edition Editor Faculty of Liberal Arts \& Professional Studies, York University, Toronto, ON, Canada 